\title{
Genome Mining and Transcriptional Analysis of Bacteriocin Genes in Enterococcus faecium CRL1879
}

Suárez N, Bonacina J, Hebert EM and Saavedra $L^{*}$

Laboratorio de Genética y Biología Molecular, CERELA-CONICET, Centro de Referencia para Lactobacilos, Chacabuco 145, San Miguel de Tucumán (T4000ILC), Tucumán, Argentina

\begin{abstract}
Among 151 bacterial isolates from nine artisanal cheeses, Enterococcus faecium CRL 1879 showed antibacterial activity against the food-borne pathogen Listeria monocytogenes. The isolate produced a proteinase K-sensitive compound in the cell free supernatant. Genome analysis demonstrated the presence of enterocin A, enterocin B, enterocin $\mathrm{P}$, enterocin SE-K4-like and enterocin X biosynthetic gene clusters. Nucleotide sequences encoding for a putative two-component bacteriocin were detected using bioinformatics tools, here named enterocin CRL1879a $\beta$. A transcriptional analysis of all bacteriocin genes by quantitative real time PCR analysis (qRT-PCR) revealed the transcription of each enterocin gene at different levels. Finally, analysis of bacteriocin genes distribution in $251 E$. faecium bioprojects was performed and compared to those identify in E. faecium CRL1879. The discriminative analysis demonstrated that bacteriocin genes are widely distributed among Enterococcus, independently of the origin of the strain.
\end{abstract}

The results presented in this paper represent a unique finding since this is the first demonstration of an E. faecium strain isolated from an artisanal cheese with the complete genetic machinery to produce six classes II and one class III bacteriocins.

Keywords: Bacteriocins; Enterococcus faecium; Genomes; Transcriptional analysis

\section{Introduction}

Enterococci are Gram-positive bacteria that commonly inhabit the gastrointestinal-tract of healthy humans and other animals. They are also associated with fermented foods, especially with dairy products such as cheese, where they are involved in flavor and aroma development. Several studies described the genus Enterococcus as the major component of the microbial community of certain Mediterranean and Hispanic cheeses [1-3].

Enterococci are known to produce a wide array of structurally diverse antimicrobial peptides, the so-called "enterocins", which may contribute to improve the hygienic and safety properties of food products [4]. Such attractive traits have increased the interest for their biotechnological use in food preservation, especially since these compounds are particularly active against food-borne pathogens, such as Listeria monocytogenes. Artisanal products and traditional fermented milk products were reported to be excellent sources for the isolation of bacteriocin- producing lactic acid bacteria (LAB) [5-7].

Bacteriocins are antimicrobial peptides produced by bacteria, which are active against closely related species. Various classifications have been reported so far based on features such as mode of action, primary structure, presence of post-translational modifications or specific anti-bacterial activity [8,9]. The structural gene of a typical bacteriocin might be part of one to three operon-type structures being usually small. In addition, these operons also contain genes encoding for proteins involved in transport, regulation and/or immunity [10].

Classical methods used to characterize LAB bacteriocins are based on the purification, determination of the molecular mass and sequencing of the potential antimicrobial peptide present in the cell-free supernatant of the bacteriocin producer strain. However, the nature of bacteriocins entails a difficult and expensive purification process. Only a few reports have focused on the in silico genomic screening of open reading frames (ORFs) encoding for potential small peptides as a new strategy to search for novel antimicrobial peptides [11,12]. In some cases, novel bacteriocin-related genes have been identified in LAB genomes [13,14]. Moreover, bacteriocin related genes in the genomes of non bacteriocin-producing strains have also been found [13].

In the present paper we described a promising Enterococcus faecium strain (CRL1879) isolated from an artisanal cheese, which displayed a remarkable antibacterial activity against the food-borne pathogen Listeria monocytogenes. The isolate produced a proteinase K-sensitive compound in the cell free supernatant. Genomic approaches were used to in silico characterize six class II bacteriocin clusters in this strain. Transcriptional analysis of all structural bacteriocin genes detected was performed in order to validate genomic finding. In addition, a careful analysis of the distribution, the presence and type of bacteriocin genes was evaluated in $251 \mathrm{E}$. faecium bioprojects and compared with those identify in E. faecium CRL1879. These data was used to subsequently examine if a set genes would be effective in predicting a category membership meaning if specific bacteriocin genes were present in niche-specific strains.

This is the first description of a food-related E. faecium (CRL1879) strain harboring six class II and one class III bacteriocin genes. The data presented here provides critical starting points for future functional studies on enterococcal bacteriocins.

*Corresponding author: Lucila Saavedra, Laboratorio de Genética y Biología Molecular, CERELA- CONICET, Tel: 54-381-4310465 ext. 169; E-mail: lucila@cerela.org.ar

Received September 25, 2015; Accepted October 12, 2015; Published October 18,2015

Citation: Suárez N, Bonacina J, Hebert EM, Saavedra L (2015) Genome Mining and Transcriptional Analysis of Bacteriocin Genes in Enterococcus faecium CRL1879. J Data Mining Genomics Proteomics 6: 180. doi:10.4172/2153-0602.1000180

Copyright: @ 2015 Suárez N, et al. This is an open-access article distributed unde the terms of the Creative Commons Attribution License, which permits unrestricted use, distribution, and reproduction in any medium, provided the original author and source are credited. 


\section{Materials and Methods}

\section{Source and maintenance of the cultures}

E. faecium CRL1879 was isolated from an artisanal cheese of Northwestern Argentina and it is deposited under CERELA Culture Collection. Listeria innocua 7 (Unité de Recherches Laitières et Génétique Appliquée, INRA France); L. monocytogenes FBUNT (Bacteriology Department, Faculty of Biochemistry, National University of Tucumán); L. monocytogenes 24 , L. monocytogenes 139 , L. monocytogenes 149, L. monocytogenes 152 (Department of Dairy and Fat Technology, Institute of Chemical Technology, Prague); $L$. monocytogenes EGD-e [15], E. coli DH10 B (Invitrogen); Staphylococcus (S) aureus. ATCC29740. E. faecium ATCC19434; E. mundtii CRL 35 [6], E. faecium CRL1, CRL6, CRL11, CRL23, CRL147, CRL316, CRL318, CRL486, CRL589, CRL1571 (CERELA Culture Collection) were used in this study. All enterococci strains were routinely cultivated in LAPTg (peptone, $15 \mathrm{~g} / \mathrm{l}$; tryptone, $10 \mathrm{~g} / \mathrm{l}$; yeast extract, $10 \mathrm{~g} / \mathrm{l}$; glucose, $10 \mathrm{~g} / \mathrm{l}$; Tween $80,0.1 \% \mathrm{v} / \mathrm{v}$; agar $1.5 \%$ ) at $37^{\circ} \mathrm{C}$. Listeria and Staphylococcus strains were grown in complex media Brain Heart Infusion broth (BHI, Britania, Buenos Aires, Argentina) at $37^{\circ} \mathrm{C}$ and E. coli $\mathrm{DH} 10$ $\mathrm{B}$ in $\mathrm{LB}$ medium $[16]$ at $37^{\circ} \mathrm{C}$ under aerobic conditions. All cultures were grown overnight. Bacterial stock cultures were maintained in $10 \%$ $(\mathrm{w} / \mathrm{v})$ skim milk with $0.5 \%(\mathrm{w} / \mathrm{v})$ yeast extract and $10 \%(\mathrm{v} / \mathrm{v})$ glycerol at $-80^{\circ} \mathrm{C}$. Agar plates were prepared using each culture medium plus $1.5 \%$ of agar (Britania, Buenos Aires, Argentina).

\section{Antimicrobial activity assays of E. faecium CRL1879}

Cell-free supernatant (CFS) of E. faecium CRL1879 was screened for antimicrobial activity by the agar diffusion assay [17] against the indicator strains. Briefly, CFS was obtained by growing E. faecium CRL1879 in LAPTg broth for $16 \mathrm{~h}$ at $37^{\circ} \mathrm{C}$. The bacterial culture was centrifuged at $15.600 \times \mathrm{g}$ for $10 \mathrm{~min}$ to obtain CFS. Then $5 \mu \mathrm{l}$ of CFS was spotted in plates containing $10 \mathrm{ml}$ of BHI $1.5 \%$ agar plus $10 \mathrm{ml}$ of BHI soft agar $(0.7 \%)$ inoculated with $10^{7}$ colony forming unit.ml ${ }^{-1}$ of an overnight culture of the indicator strains. Plates were incubated for 24 $\mathrm{h}$ at the corresponding incubation temperature and examined for clear zones of growth inhibition. In order to characterize the antimicrobial compound, aliquots of $200 \mu \mathrm{l}$ of CFS were a) adjusted to $\mathrm{pH} 7.0$ with $1 \mathrm{~N}$ $\mathrm{NaOH}$ and b) added $1000 \mathrm{U} \mathrm{ml}^{-1}$ of catalase, c) treated with proteinase $\mathrm{K}\left(20 \mathrm{mg} \cdot \mathrm{ml}^{-1}\right.$-Invitrogen, Buenos Aires, Argentina) at $42^{\circ} \mathrm{C}$ for $2 \mathrm{~h}, \mathrm{~d}$ ) heated at $100^{\circ} \mathrm{C}$ for $5 \mathrm{~min}$ (most bacteriocins are heat stable). In all the cases, a positive control (fresh unmodified CFS) was tested in parallel. The inhibitory activity of each sample was determined by the spot-onlawn assay as described above.

\section{In silico identification of bacteriocin genes in $E$. faecium CRL1879 genome}

E. faecium CRL1879 genome sequence is deposited at Genbank (AN AOUK00000000.1). Genes encoding bacteriocins and post translationally modified peptides (RiPPs) or those related with their production systems were search in E. faecium CRL1879 genome. Rapid Annotations using Subsystem Technology server (RAST) and BAGEL3 software Linux version were used to perform the analysis $[18,19]$. Putative promoter regions were analyzed with Promoter Prediction by Neural Network (NNPP) and BPROM (Softberry Inc., Mount Kisco, NY, USA) [20]. Bacteriocin sequence analyses were done with the bacteriocin database $[21,22]$. The analysis of the nucleotide sequences, translation and alignments were performed with DNASTAR software version 11.2.1.25 (DNASTAR Inc., USA). The identity of sequences was analyzed using Blastx service from the NCBI database.

\section{Transcriptional analysis of bacteriocin genes in E. faecium CRL1879}

RNA isolation: Total RNA was extracted from E. faecium CRL 1879 according to Raya et al. from three independent cultures and separated into at least two technical repeats [23]. Briefly, cells from 50 $\mathrm{ml}$ of a culture of $12 \mathrm{~h}$ were harvested by centrifugation, washed with TE buffer (10 mM Tris, $1 \mathrm{mM}$ EDTA; $\mathrm{pH} 8.0)$ and suspended in 500 $\mu \mathrm{l}$ of cold TE buffer. The cell suspension was added to a $2-\mathrm{ml}$ screwcap microcentrifuge tube containing $0.6 \mathrm{~g}$ of glass beads $(0.1-\mathrm{mm}$ diameter), $170 \mu \mathrm{l}$ of $2 \%$ macaloid slurry, $500 \mu \mathrm{l}$ of Tris-HCl buffered phenol-chloroform (1:1), and $50 \mu \mathrm{l}$ of $20 \%$ sodium dodecyl sulfate. Cells were disrupted by shaking in a Mini-Beadbeater Cell Disrupter (Model 607EUR, Biospec Products, Barttlesville, Okla, USA) during 6 cycles of $1 \mathrm{~min}$ of disruption following by $1 \mathrm{~min}$ on ice. After centrifugation at $15.600 \times \mathrm{g}, 4^{\circ} \mathrm{C}$ for $15 \mathrm{~min}$, the aqueous supernatant containing the RNA was two times extracted with 1volume of phenol-chloroform and precipitated with sodium acetate $3 \mathrm{M}, \mathrm{pH} 5.2$ and absolute ethanol. Finally, RNA was suspended in RNAse free water. The isolated RNA was treated with TURBO DNA-free ${ }^{\mathrm{Tx}}$ kit (Ambion", Invitrogen, Buenos Aires, Argentina) according to the manufacturer's instructions, before the first-strand synthesis of cDNA.

qRT- PCR: Synthesis of cDNA were performed from $100 \mathrm{ng}$ of total DNA-free RNA, using qScript ${ }^{\mathrm{TM}}$ CDNA SuperMix (QuantaBiosciences, Genbiotech, Argentina). The primers used in qRT-PCR are listed in (Table 1). These were designed according to the ent $A$, ent $B$, entP, ent entSE-K4, ent $X \alpha \beta$ and entCRL1879 $\alpha \beta$ sequences according to the genome sequence of E. faecium CRL1879 with Primer Quest software (Integrated DNA Technologies, Inc.). [26]. qRT-PCR reactions were performed in duplicates using $35 \mathrm{ng} \mathrm{cDNA}, 0.3 \mu \mathrm{M}$ of each primer and $10 \mu \mathrm{l}$ of qPCR MasterMix (PerfeCta ${ }^{\circ} \mathrm{SYBR}^{\circ}$ Green Supermix for $\mathrm{iQ}^{\mathrm{TM}}$ - Quanta Biosciencs ${ }^{\mathrm{TM}}$, Genbiotech, Argentina) on a final volume of $20 \mu \mathrm{l}$ per reaction. Reactions were run on an $\mathrm{IQ}^{\mathrm{TM}} 5$ Multicolor RealTime PCR Detection System (BioRad, USA). PCR conditions were: initially $2 \mathrm{~min} / 50^{\circ} \mathrm{C}, 3 \mathrm{~min} / 95^{\circ} \mathrm{C}, 40$ cycles consisting of $10 \mathrm{~s} / 95^{\circ} \mathrm{C}$, $30 \mathrm{~s} / 50^{\circ} \mathrm{C}$ following by a melting curve temperature cycles. For each reaction, a non-template control (NTC) was included (without cDNA) and the invariable expression of 16S rRNA under the test conditions (data not shown) was used as house-keeping gene. Standard curves for ent $A$, ent $B$, entP, entSE-K4, entX $\alpha \beta$ and entCRL1879 $\alpha \beta$ genes were performed in order to determine the copy number of each transcript. These genes were amplified by PCR from E. faecium CRL 1879 genomic DNA and purified using the Wizard ${ }^{\circ}$ SV Gel and PCR Clean-Up System kit (Promega, Madison-USA). All primers and standard curves for qRT-PCR assay displayed efficiencies between 98 and 110\%. A single product-specific melting curve was obtained for each primer set. The concentration of the amplified product was measured with a UVvisible spectrophotometer (Varian, 50MPR Microplate Reader -Cary) at $260 \mathrm{~nm}$ using a standard calibration curve, and converted to number of copies per unit volume using the following equation:[25].

DNA $($ copy $)=\left(6.023 \times 10^{23}\right.$ [copies $\left.\mathrm{mol}^{-1}\right] \times$ DNA amount $\left.[\mathrm{g}]\right) /$ (DNA length [bp] x $660\left[\mathrm{~g} \mathrm{~mol}^{-1} \mathrm{bp}^{-1}\right]$ )

The concentration of the purified linear dsDNA standards was adjusted to $10^{10}$ copies per $\mu$. This stock solution was tenfold serially diluted to obtain a standard series from $10^{10}$ to $10^{4}$ copies per $\mu$ land it was used to construct the standard curves for enterocin structural genes. Each standard dilution was analyzed in duplicate. The $\mathrm{Ct}$ values were plotted against the logarithm of their initial template copy concentration to generate each standard curve by a linear regression. 
Citation: Suárez N, Bonacina J, Hebert EM, Saavedra L (2015) Genome Mining and Transcriptional Analysis of Bacteriocin Genes in Enterococcus faecium CRL1879. J Data Mining Genomics Proteomics 6: 180. doi:10.4172/2153-0602.1000180

Page 3 of 8

\begin{tabular}{|c|c|c|c|}
\hline Primers & Nucleotide sequence & Product size (bp) & Reference \\
\hline Enterocin A & $\begin{array}{l}\text { F: 5' AATATTATGGAAATGGAGTGTATTGC 3' } \\
\text { R: 5' TTGCCTTGGCCCAATCGACC 3' }\end{array}$ & 68 & \multirow[t]{9}{*}{ This study } \\
\hline Enterocin B & $\begin{array}{l}\text { F: 5' CAGAATGCCTAATGAGTTAAATAGACC 3' } \\
\text { R: 5' AGAGTATACATTTGCTAACCCAGC 3' }\end{array}$ & 138 & \\
\hline Enterocin $\mathrm{P}$ & $\begin{array}{l}\text { F: 5' GATGCAGCTACGCGTTCATATGGT 3' } \\
\text { R: 5' CAAACCAGAAGCCCAGCCACTAAT 3' }\end{array}$ & 98 & \\
\hline Enterocin SE-K4 & $\begin{array}{l}\text { F: 5' GGCTCAGTTATTTGTAGCATGATTGGG 3' } \\
\text { R: 5'CACACCATTTCCGTAATACGTGGC 3' }\end{array}$ & 86 & \\
\hline Enterocin CRL1879 a & $\begin{array}{l}\text { F: 5' CTGGCTGGGATGCTCGAA 3' } \\
\text { R: 5' GTGGACTTACCACAGGGGCA 3' }\end{array}$ & 128 & \\
\hline Enterocin CRL1879 $\beta$ & $\begin{array}{l}\text { F: 5' GGATTCAGCATGTGGACCGG 3' } \\
\text { R: 5'GGCACTACTTTTTCTGGGGC 3' }\end{array}$ & 121 & \\
\hline Enterocin Xa & $\begin{array}{l}\text { F: 5' ACTTCTACAGATTCAAGGAGGAATAG 3' } \\
\text { R: 5'CTGAGTGATCCCATGCATCTT 3' }\end{array}$ & 93 & \\
\hline Enterocin $X \beta$ & $\begin{array}{l}\text { F: 5' CTTTGGTATGGTGTAGGACAATTTATG 3' } \\
\text { R: 5'CCAGGAATTATCATGTGTTTAACAGG 3' }\end{array}$ & 93 & \\
\hline 16s rDNA & $\begin{array}{l}\text { F: 5' ATTGCCGAAGATTCCCTACTG 3' } \\
\text { R: 5' GCATTAGCTAGTTGGTGAGGT 3' }\end{array}$ & 135 & \\
\hline
\end{tabular}

Table 1: qRT- PCR specific primers used in this study.

\begin{tabular}{|c|c|c|}
\hline \multirow{3}{*}{ Sensitive strains } & \multicolumn{2}{|c|}{ Antimicrobial Activity (mm) } \\
\hline & ATCC & \multirow{2}{*}{ CRL 1879} \\
\hline & 19434 & \\
\hline E. coli $\mathrm{DH} 10 \mathrm{~B}$ & - & - \\
\hline E. faecium ATCC19434 & - & - \\
\hline E. faecium CRL1 & - & - \\
\hline E. faecium CRL6 & - & ++ \\
\hline E. faecium CRL11 & - & ++ \\
\hline E. faecium CRL23 & - & + \\
\hline E. faecium CRL147 & - & - \\
\hline E. faecium CRL316 & - & + \\
\hline E. faecium $\mathrm{CRL} 318$ & - & ++ \\
\hline E. faecium CRL486 & - & ++ \\
\hline E .faecium CRL589 & - & ++ \\
\hline E. faecium CRL1571 & - & ++ \\
\hline E. mundtii CRL35 & - & + \\
\hline L. innocua 7 & + & + \\
\hline L. monocytogenes 139 & + & + \\
\hline L. monocytogenes 149 & + & + \\
\hline L. monocytogenes 152 & + & + \\
\hline L. monocytogenes 24 & + & + \\
\hline L. monocytogenes EGD-e & - & - \\
\hline L. monocytogenes FBUNT & + & ++ \\
\hline S. aureus ATCC29740 & - & - \\
\hline
\end{tabular}

database were analyzed by BAGEL3 software Linux version, BLASTx algorithm and bacteriocin database Bactibase [20-23] (Table S1). The resulting data from BAGEL3 was subjected to linear discriminant analysis (LDA). LDA was used to establish whether the presence of a set of $b a c$ genes was effective in predicting category membership, i.e, specific bac genes present in niche-specific strain. LDA was performed with Statistica 10.0 software. The discrete distribution of bac genes among strains isolated from human, animal, food and those of unknown provenance was determinate. All genomes analyzed were previously classified depending on the origin of isolation of the strains, i.e, animal (AN); human (H); food (F) sources and strains with unknown provenance (U) (Table S2).

\section{Results}

\section{Antibacterial activity of $E$. faecium CRL1879}

E. faecium CRL1879 was isolated from an artisanal cheese made in Northwestern region of Argentina. This strain was selected due to the interesting antimicrobial activity observed in cell free supernatant (CFS); E. faecium ATCC19434 (enterocin A and B producer, unpublished data) was used as positive control (Table 2). All L. monocytogenes strains, including biofilm-forming strains $24,139,149,152$, were sensitive to CFS except EGD-e strain. Regarding enterococci used as indicators, it is surprisingly that CFS from CRL1879 turned out to be active against almost all strains tested as compared to the antimicrobial activity of the ATCC19434 CFS, suggesting the potential production of different antimicrobial compounds among strains. On the other hand, CFS did not show antimicrobial activity against E.coli DNH10B, S. aureus ATCC 29740. To further characterize the antimicrobial compound, CFS aliquots were i) neutralized to $\mathrm{pH} 7$, ii) treated with catalase and iii) with proteinase $\mathrm{K}$ and tested against L. monocytogenes FBUNT. Untreated CFS from CRL1879 was used as positive control. Growth inhibition halos were only sensitive to proteinase $\mathrm{k}$ demonstrating that the antimicrobial compound present in CFS was of proteinaceous nature, likely a bacteriocin.

\section{Genome identification of bacteriocin production systems in E. faecium CRL 1879}

The genome sequence of $E$. faecium CRL 1879 was acquired using a whole-genome shotgun (WGS) strategy with an Ion Torrent personal genome machine. Quality filtered reads were in silico assembled 
Citation: Suárez N, Bonacina J, Hebert EM, Saavedra L (2015) Genome Mining and Transcriptional Analysis of Bacteriocin Genes in Enterococcus faecium CRL1879. J Data Mining Genomics Proteomics 6: 180. doi:10.4172/2153-0602.1000180

using the DNASTAR Ngen assembler, giving 73 large contigs (AN AOUK00000000.1) [24]. RAST Server, Blast algorithms and BAGEL3 analysis demonstrated the existence of enterocin $\mathrm{P}$, enterocin $\mathrm{B}$, enterocin $X \alpha \beta$, enterocin $A$ and enterocin SE-K4-like biosynthetic clusters (Figure 1).

Sequence analysis of the enterocin P gene cluster (contig_152, AN AOUK01000025) revealed the same genetic organization as previously described by Cintas et.al. [26] (Figure 1). The deduced amino acid sequence of entP gene showed $95 \%$ identity to enterocin $\mathrm{P}$ described by Cintas et al. with two amino acids changes in the leader peptide at positions $9(\mathrm{~A}-\mathrm{T})$ and $13(\mathrm{I}-\mathrm{K})$ and one at the position $69(\mathrm{M}-\mathrm{I})$ of the mature peptide [26].

Enterocin B biosynthetic cluster from E. faecium CRL1879 (contig_71, AN AOUK01000001) was identical to the one previously described by Franz et al. [27]. By using the software BAGEL 3, genomic sequence analysis of the same contig revealed the presence of ORFs encoding for two -component bacteriocins, enterocin $\mathrm{X}$ previously described in E. faecium KU-B5 [28]. A putative immunity gene for enterocin $\mathrm{X}$ (entiX) was located 584 nucleotides upstream of the enterocin $B$ precursor gene, in the same direction. The putative two components of enterocin X locus containing enterocin Xa (entX $\alpha)$ and the enterocin $\mathrm{X} \beta$ genes (entX $\beta$ ) was located upstream entiX (Figure 1).

BLAST and RAST analysis of contig_191 (AN AOUK01000051) demonstrated that a fragment of 700 bp display $94 \%$ of identity with E. faecalis pAMS1 (NG_036515.1) and 92\% with pEK4S (AB092692.1) plasmids, both known for their bacteriocin-encoding genes $[29,30]$. The biosynthetic cluster of this enterocin SE-K4-like bacteriocin is organized in an operon-like structure consisting in two consecutive ORFs (Figure 1). The first ORF 1 encodes a 71 amino acid protein corresponding to enterocin SE-K4-like pre-peptide. The deduced amino acid sequence of the putative bacteriocin encoding gene in CRL1879 genome exhibited only $77 \%$ of identity to enterocin SE-K4 first described in E. faecalis K4 (BAC20326.1) with six amino acid deletion at the C-terminal domain (Figure 1). However, this nucleotide sequence is widely distributed and conserved among E. faecium genomes strains deposited at NCBI (EEV57603.1, EFF32511.1, EFR67967.1, EJX61666.1, EJX72841.1, among others). ORF2 gene, encoding a putative immunity protein composed of 113 amino acids, was immediately found downstream of the bacteriocin gene. A putative ribosome binding site (RBS) for the bacteriocin structural gene (AAGGTG) was located 7 bases upstream of the initiation codon. Possible -10 and -35 promoter sequences were also detected.

The enterocin A locus was located in contig_279 (AN AOUK01000059) (Figure 2). Sequence analysis showed the presence of two putative operons: (I) the bacteriocin operon with the enterocin A gene (ent $A$ ), the immunity gene (entI), and three component regulatory system the peptide pheromone gene (entF), the histidine protein kinase gene (entK), and the response regulator (entR), and (II) the transporter operon consisting of the two genes, the $\mathrm{ABC}$ transporter (ent $T$ ) and its accessory gene (entD) as previously described by O' Keeffe et al. [31]. Analysis of $1474 \mathrm{bp}$ intergenic sequence located between enterocin A-regulatory and transport operons revealed three consecutive ORFs oriented in opposite direction to the complete entA cluster. Both, ORF 1 and ORF2, encode putative double-glycine-type pre-peptide with a 19 and 21-residue leader sequence with theoretical pI/MW 9.31/5141.86 and 7.78/4338.99, respectively (Figure 2). Although deduced amino acid sequence of ORF1 showed 97-99\% identity with annotated as putative bacteriocin-like proteins present in several $E$. faecium genomes (YP_008396028.1; YP_007395047.1; EEV45206.1;

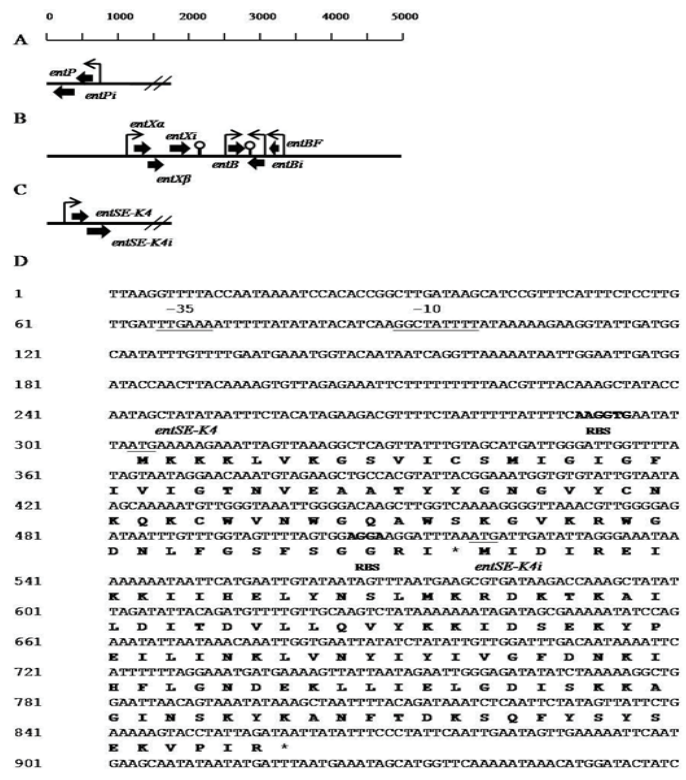

Figure 1: Genetic organization of gene clusters associated with enterocin production in E. faecium CRL 1879 draft genome. Graphic illustration of the genes involved in the production, immunity and transport of enterocin $P(A)$, enterocin $X$ and enterocin $B(B)$; enterocin SE-K4 (C) are represent. Potential transcriptional terminators structures are indicated by a stem-loop vertical line and promoters are indicated by an arrow. (D) Nucleotide sequence of the enterocin SE-K4 gene and of the putative immunity protein gene. The translation products of both genes are also shown. The putative -10 and -35 promoter sequences are underlined; ribosome binding sites (RBS) are boldface.

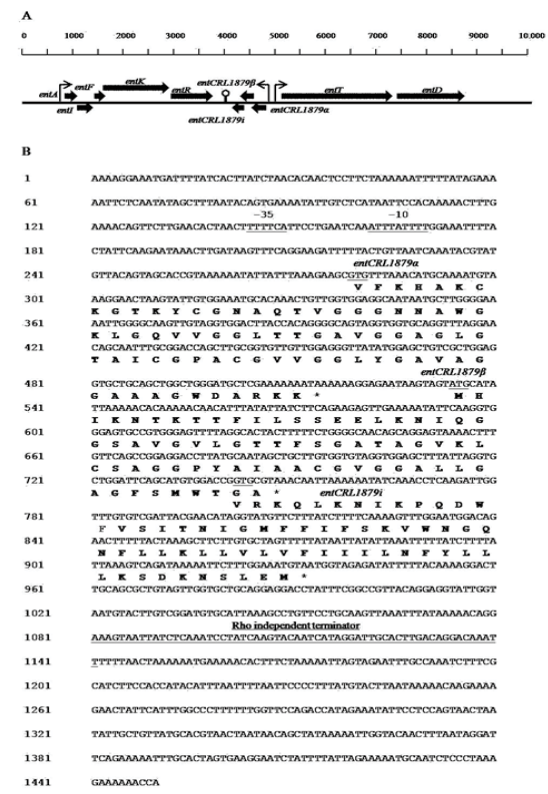

Figure 2: Genetic organization of enterocin A and enterocin CRL1879a $\beta$ gene cluster in E. faecium CRL 1879 draft genome (A). Potential transcriptional terminators structures are indicated by a stem-loop vertical line and promoters are indicated by an arrow. (B) Nucleotide sequence of the 1450-bp fragment containing both enterocin CRL1879 structural genes (ent1879a, ent1879ß) and the putative immunity gene (orf3) is represent. The deduced amino acid sequences of enterocin CRL1879 and ORF3 are shown. The putative -10 and -35 promoter sequences and Rho independent terminator sequence are underlined. 
EEF20746.1), no clear homology was found to any biochemically characterized bacteriocin. ORF2 deduced amino acid sequence showed 97-99\% identity with hypothetical proteins (YP_007395046.1; YP_008396027.1; EEV45207.1) but no homology to any previously known bacteriocin. Sequence analysis of the deduced amino acid sequence of these two putative peptides also showed the GXXXG motif, suggested to be involved in helix-helix interaction between two component bacteriocins [32]. No obvious rho-independent transcriptional terminator (invert repeats) was found between ORF1 and ORF2 suggesting that may belong to the same transcriptional unit. Thus, we named here enterocin CRL1879 $\alpha \beta$ as a potential twocomponent bacteriocin. In addition, ORF3 located downstream of ORF2 predicted a 63-residue, hydrophobic and cationic (pI 10.47) protein with one putative trans-membrane domain resembling an immunity-like protein, but no sequence identity could be determined either.

\section{E. faecium CRL 1879 expresses multiple bacteriocin genes}

In order to validate genomic findings we performed transcriptional analyses of all putative bacteriocin genes found in E. faecium CRL 1879. qRT-PCR experiments revealed the presence of entP, entSE-K4, entB, ent $A$, ent $X \alpha \beta$ subunits as well as entCRL1879 $\alpha \beta$ transcripts (Table 3 ). The gene encoding for the enterocin $\mathrm{P}$ structural peptide presented the highest level of expression $\left(2.410^{7}\right.$ copies $\left.\mu{ }^{-1}\right)$, while enterocin $X \alpha$ and $X \beta$ gene transcripts were present in an order of $1.6 \times 10^{6}$ and $2.7 \times 10^{6}$ copies $\mu \mathrm{l}^{-1}$ respectively. The entA gene was transcript in an order of 2.4 $10^{5}$ copies $\mu \mathrm{l}^{-1}$. Interestingly, entCRL1879 $\alpha \beta$ genes were transcript at $7.7 \times 10^{5}$ and $7.4 \times 10^{5}$ copies $\mu \mathrm{l}^{-1}$, entSE-K4 transcript was present at $2.510^{5}$ copies $\mu \mathrm{l}^{-1}$ and finally ent $B$ transcript was in an order of $9.210^{4}$ copies. $\mu^{-1}$.

\section{Comparative genomic analysis of putative bacteriocin genes among E. faecium strains}

A detailed in silico analysis of the distribution, the presence and type of $b a c$ genes was evaluated in E. faecium bioprojects and compared with those identify in E. faecium CRL1879. 251 partial or complete E. faecium genomes, deposited at the NCBI Genome database, from different origin were mine searching bacteriocin genes using BAGEL3 software and BLASTx algorithm (Table S1). Exhaustive analysis demonstrated that i) almost all strains contain one to six putative bacteriocin genes except to PRJNA82503 and PRJNA179542 which exhibited no putative bacteriocin genes ii) 24 bacteriocin class II encoding genes and one for enterolysin $\mathrm{A}$, a class III bacteriocin, were detected; iii) known enterocins (enterocin A, B, P SE-K4, X, NKR5-3A, L50A and B) showed a highly conserved sequence among the genus; iv) not all strains carrying enterocin $A$ genes have enterocin $B$ gene v) enterolysin A, a bacteriolysin, is widely distributed among $E$. faecium genomes; vi) as a general rule, enterocin $X \alpha \beta$ is disseminated among $E$. faecium strains that concomitantly harbors ent $B$ gene. One strain showed enterocin $X \alpha \beta$ in the absence of entB gene. Conversely, six genomes showed only ent $B$ gene; vii) interestingly, we found genes encoding for bacteriocins described in the Lactobacillus genus (sakacin Q and sakacin T) and viii) E. faecium CRL1879 is the only food related strain harboring six class II and one class III bacteriocin genes. The resulting data from BAGEL3 was subjected to LDA statistical analysis. Each individual strain was a priori classified according to its origin of isolation (Table S1). Once each bacteriocin gene was detected by BAGEL3, LDA was used to establish whether the presence of a set of bac genes was effective in predicting category membership i.e. the origin of a strain (Figure3) (Table S2). This analysis measure the percentage of similarities according to the presence or absence of variables used to identify each individual. Results demonstrated that $53 \%$ of strains analyzed were classified in the same groups as the $a$ priori classification (Table 4 ). LDA showed that $63.33 \%$ of total strains a priori classify as Human could be assigned in the same group. However, the discriminative analysis demonstrated bacteriocin genes are widely distributed among Enterococcus, independently of the origin of the strain and there is no strong association between the origin and the number of bacteriocin genes present in a specific strain.

\section{Discussion}

Northwestern Argentinean chesses have been prolific substrates where numerous LAB strains with technological properties were isolated and characterized [17]. Several studies described the genus

\begin{tabular}{|c|c|c|c|c|c|c|c|c|}
\hline \multirow[t]{4}{*}{ E. faecium CRL1879 } & \multicolumn{8}{|c|}{ Ct and estimated enterocin copy number by RT-PCR absolute quantification* } \\
\hline & \multicolumn{8}{|c|}{ Bacteriocin mRNA copies (copies $\mu l^{-1}$ ) } \\
\hline & ent $A$ & entB & entP & entSE-K4 & entXa & entX $\beta$ & ent1879a & ent1879 $\beta$ \\
\hline & $2.4 \times 10^{5}$ & $9.2 \times 10^{4}$ & $2.4 \times 10^{7}$ & $2.5 \times 10^{5}$ & $1.6 \times 10^{6}$ & $2.7 \times 10^{6}$ & $7.7 \times 10^{5}$ & $7.2 \times 10^{5}$ \\
\hline
\end{tabular}

*Estimated copy number of enterocin genes transcripts in E. faecium CRL 1879 cells at laboratory conditions, by RT-PCR absolute quantification.

Table3: Enterocin transcripts copy number obtained by qRT-PCR.

\begin{tabular}{|c|c|c|c|c|c|}
\hline \multirow{3}{*}{$\begin{array}{c}\text { A priori } \\
\text { classification }^{*}\end{array}$} & & \multicolumn{4}{|c|}{ Classification Matrix } \\
\hline & & \multicolumn{4}{|c|}{ Predicted Category Classifications by LDA } \\
\hline & $\begin{array}{l}\% \text { of strains } \\
\text { defined in the } \\
\text { corresponding } \\
\text { category } \\
\text { classification }^{* *}\end{array}$ & Human (H) & Unknown (U) & Animal (AN) & Food (F) \\
\hline $\mathbf{H}$ & 63.6 & 77 & 11 & 28 & 5 \\
\hline $\mathbf{U}$ & 26.9 & 34 & 18 & 8 & 7 \\
\hline AN & 65.4 & 14 & 2 & 34 & 2 \\
\hline $\mathbf{F}$ & 45.4 & 4 & 2 & 0 & 5 \\
\hline Total & 53.4 & 129 & 33 & 70 & 19 \\
\hline
\end{tabular}

*: A priori classification according to the strain isolation source information obtained from the Bioproject at the NCBI Genome data base.

**: Percentage of strains that effectively correspond to their a priori established classification after the LDA analysis.

Table 4: Predicted category classifications of Enterococcus strains harboring bacteriocin genes by LDA. 


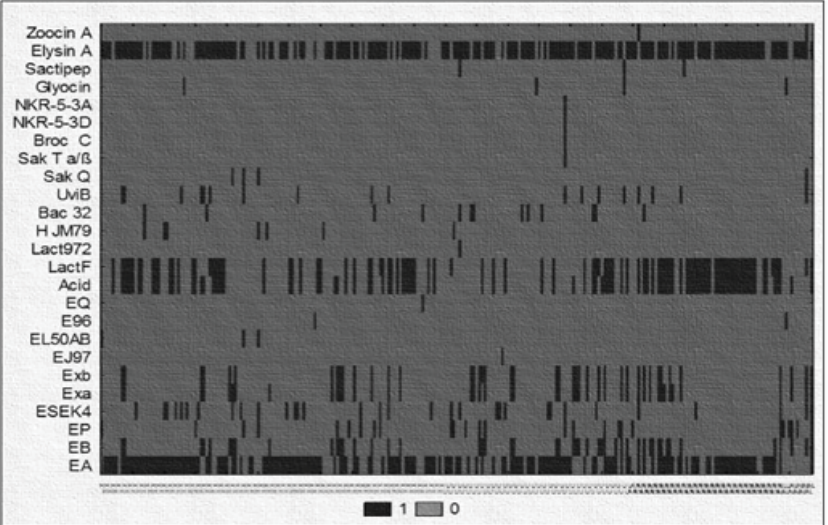

Figure 3: Raw discrete data plot performed with Statistica 10.0 software. Each data point in this plot is represented as a rectangular region with two different colors, black or grey, that correspond to the 1 or 0 values which indicate the presence or absence of bac genes for each of the E. faecium genomes classified as animal (AN); human (H); food (F) sources and strains with unknown provenience $(U)$ depending on the origin of isolation of the strains. Values within each series are presented along the x-axis, with each series plotted along the $y$-axis. Bacteriocin genes identified: enterocin A (EA), enterocin B (EB), enterocin P (EP), enterocin SE-K4 (ESEK4), enterocin $\mathrm{Xa}(\mathrm{Exa})$, enterocin $X \beta$ (Exb), enterocin $E J 97$ (EJ97), enterocin L50A_B (EL50AB), enterocin 96 (E96), enterocin Q (EQ), acidocin LF221BgassericinK7B (Acid), lactacin_F subunit (LacF), lactococcin 972 (Lac972), hiracin JM79 (HJM79), bac 32, uvicin B (UviB), sakacin Q (SakQ), sakacin T $\alpha / \beta$ (Sak $a / b)$, brococin $C$ (BroC), enterocin NKR-5-3D, enterocin NKR-5-3A, glyocin, sactipeptides (Sactipep), enterolysin A (Elysin A), zoocin A.

Enterococcus as the major component of the microbial community of certain Mediterranean and Hispanic cheeses [2,3,33]. The predominance of enterococci into the microbial population of various fermented foods such as meat or cheese can be explained by the frequent production of bacteriocins, as well as its tolerance to heat, dry and saline environments [34,35]. In the present paper, we demonstrated that CFS of CRL1879 strain is active against six different Listeria strains including biofilm-forming bacteria (strains 139, 149, 152, 24) except to the widely used L. monocytogenes EGD-e. In contrast, CFS was not active against $E$. coli DNH10B neither to $S$. aureus ATCC 29740 used as indicator strains. In general, bacteriocins produced by Gram-positive bacteria have no effect on Gram-negative bacteria without the addition of any membrane-active compound, but there is some exceptions to the rule [36].

E. faecium CRL1879 strain have known structural genes encoding for class II bacteriocins: enterocin A, enterocin B, enterocin P, enterocin $\mathrm{X}$ and enterocin SE-K4-like. Enterocin A and B first discovered and identified in E. faecium T136 are frequently present in E. faecium strains from various sources $[37,38]$. Enterocin $\mathrm{P}$ is a sec-dependent bacteriocin widely distributed among E. faecium strains. We have previously shown that the presence of more than one bacteriocin gene in Enterococcus genus is a common finding [39]. Interestingly, the gene encoding for enterocin SE-K4 was only described in E. faecalis strains [29]. The co-existence of genes encoding for the production of enterocin SE-K4-like bacteriocin with other bac genes in E. faecium strains have not been described in the literature yet. To our knowledge, this is the first report of an E. faecium strain that possess the structural gene encoding for enterocin SE-K4-like bacteriocin.

Since the first enterococcal genome sequenced - that of Enterococcus faecalis V583, now a veritable avalanche of complete or draft genome sequences of various enterococcal strains and species are available [40]. Recently as part of this paper, E. faecium CRL1879 genome has been sequenced by a whole-genome shotgun [24]. Based on these data, in silico screening strategies were employed to mine for bacteriocins or ORFs encoding for potential small peptides in DNA sequences using specially designed software such as BAGEL [20]. Genome sequence analysis of $E$. faecium CRL1879 confirmed the presence of gene clusters involved in enterocin P, B, A and SE-K4-like bacteriocin production, transport and immunity. They are chromosomally encoded and they show high degree of similarity to those previously described in the literature except for enterocin SE-K4 as described in the results section. In addition, a gene cluster encoding for enterocin $\mathrm{X}$ production was also found. Enterocin X cluster was located in the vicinity of enterocin $\mathrm{B}$ in similar fashion as previously described in the literature [28]. BAGEL 3 analyses also revealed a potential two-component bacteriocin at the intergenic sequence located between enterocin A-regulatory and transport operons. Although, three consecutive ORFs (ent CRL1879 $\alpha \beta$ and CRL1879 ${ }_{\text {imm }}$ ) oriented in opposite direction to the complete entA cluster are present in several E. faecium genomes, we demonstrated that ent CRL1879 $\alpha \beta$ are transcribed under our laboratory conditions (Table S2). Transcriptional analyses showed also that entP transcript showed the highest copy number which might be explained since enterocin $\mathrm{P}$ is exported via the general secretory (Sec-dependent) pathway. Such a mechanism of export is potentially beneficial to the host due to its apparent metabolic and genetic economy. Only a few studies have analyzed the transcriptional profile of the bacteriocin production in LAB. A reverse transcription-PCR analysis showed the expression of ent $A$, entB, and munKS bacteriocin genes in E. faecium CWBI-B1430 and entP and munKS genes in E. mundtii CWBI-B1431 [41]. Moreover, enterococcal strains characterized in the literature so far bear up to four bacteriocin genes $[42,9]$. qRT-PCR results obtained here validated the in silico bacteriocin genome findings demonstrating that the $E$. faecium CRL 1879 strain isolated from an Argentinean northwestern artisanal cheese possess the complete genetic machinery necessary to produce six antimicrobial peptides.

Enterococci are known to produce a wide array of structurally diverse antimicrobial peptides [26]. This fact was here validated by the number and type of putative bacteriocin genes found in enterococcal genomes by BAGEL3 analysis. Enterocin A and B were considered as hallmark genes of this genus; however we found that not all strains carrying enterocin A genes have enterocin B gene as previously described by other authors [43]. Another interesting fact is that we found that genes of enterocin $X \alpha \beta$ and its immunity protein are located in the vicinity of enterocin B gene cluster in E. faecium CRL1879. Genomewide analysis revealed that enterocin X $\alpha \beta$ previously described in $E$. faecium KU-B5 is widely distributed among E. faecium strains that concomitantly harbors entB gene [28]. Exceptions to this rule are only six strains that contain only enterocin $B$ gene. We also detected enterolysin A, a bacteriolysin, extensively distributed among $E$. faecium genomes besides its previous characterization only in E. faecalis strains [44]. In addition, we found genes encoding for bacteriocins described in the Lactobacillus genus such as sakacin Q and sakacin $\mathrm{T}$ besides those previously described in Enterococcus.

In summary, bacteriocin genes are extensively distributed among Enterococcus genus, independently of the origin of the strain and there is no strong association between the origin and the number of bacteriocin genes present in a specific strain. This is first demonstration of a bacterial strain, E. faecium CRL 1879, able to produce six class II bacteriocins. E. faecium CRL 1879 has a promising potential in food preservation. Ongoing research is evaluating the bacteriocin producing 
Citation: Suárez N, Bonacina J, Hebert EM, Saavedra L (2015) Genome Mining and Transcriptional Analysis of Bacteriocin Genes in Enterococcus faecium CRL1879. J Data Mining Genomics Proteomics 6: 180. doi:10.4172/2153-0602.1000180

machinery in a model food system.

\section{Acknowledgments}

This study was carried out with the financial support from CONICET (PIP0406/12) and MinCyT (PICT2011 N0175) from Argentina

Authors are grateful to Lic. Elena Bru for her collaboration with statistical analysis.

\section{References}

1. Abriouel $H$, Martin-Platero $A$, Maqueda $M$, Valdivia $E$, Martinez-Bueno $M$ (2008) Biodiversity of the microbial community in a Spanish farmhouse cheese as revealed by culture-dependent and culture-independent methods. Int J Food Microbiol 127: 200-208

2. Casalta E, Sorba JM, Aigle M, Ogier JC (2009) Diversity and dynamics of the microbial community during the manufacture of Calenzana, an artisanal Corsican cheese. Int J Food Microbiol 133: 243-251.

3. Renye JA, Jr., Somkuti GA, Paul M, Van Hekken DL (2009) Characterization of antilisterial bacteriocins produced by Enterococcus faecium and Enterococcus durans isolates from Hispanic-style cheeses. J Ind Microbiol Biotechnol 36: 261-268.

4. Hauge HH, Nissen-Meyer J, Nes IF, Eijsink VG (1998) Amphiphilic alphahelices are important structural motifs in the alpha and beta peptides that constitute the bacteriocin lactococcin $\mathrm{G}$ enhancement of helix formation upon alpha-beta interaction. Eur J Biochem 251: 565-572.

5. Andrighetto C, Knijff E, Lombardi A, Torriani S, Vancanneyt M, et.al. (2001) Phenotypic and genetic diversity of enterococci isolated from Italian cheeses. J Dairy Res 68: 303-316.

6. Saavedra L, Minahk C, de Ruiz Holgado AP, Sesma F (2004) Enhancement of the enterocin CRL35 activity by a synthetic peptide derived from the $\mathrm{NH}_{2}$ terminal sequence. Antimicrob Agents Chemother 48: 2778-2781.

7. Terzic-Vidojevic A, Vukasinovic M, Veljovic K, Ostojic M, Topisirovic L (2007) Characterization of microflora in homemade semi-hard white Zlatar cheese. Int J Food Microbiol 114: 36-42.

8. Cotter PD, Hill C, Ross RP (2005) Bacteriocins: developing innate immunity for food. Nat Rev Microbiol 3: 777-788.

9. Perez RH, Himeno K, Ishibashi N, Masuda Y, Zendo T, et.al. (2012) Monitoring of the multiple bacteriocin production by Enterococcus faecium NKR-5-3 through a developed liquid chromatography and mass spectrometry-based quantification system. J Biosci Bioeng 114: 490-496.

10. Snyder AB, Worobo RW (2014) Chemical and genetic characterization of bacteriocins: antimicrobial peptides for food safety. J Sci Food Agric 94: 28-44.

11. Begley M, Cotter PD, Hill C, Ross RP (2009) Identification of a novel twopeptide lantibiotic, lichenicidin, following rational genome mining for LanM proteins. Appl Environ Microbiol 75: 5451-5460.

12. Marsh AJ, O'Sullivan O, Ross RP, Cotter PD, Hill C (2010) In silico analysis highlights the frequency and diversity of type 1 lantibiotic gene clusters in genome sequenced bacteria. BMC Genomics 11: 679 .

13. Chaillou S, Champomier-Verges MC, Cornet M, Crutz-Le Coq AM, Dudez AM et.al. (2005) The complete genome sequence of the meat-borne lactic acid bacterium Lactobacillus sakei 23K. Nat Biotechnol 23: 1527-1533.

14. Diep DB, Godager L, Brede D, Nes IF (2006) Data mining and characterization of a novel pediocin-like bacteriocin system from the genome of Pediococcus pentosaceus ATCC 25745. Microbiology 152: 1649-1659.

15. Glaser P, Frangeul L, Buchrieser C, Rusniok C, Amend A, et.al (2001) Comparative genomics of Listeria species. Science 294: 849-852.

16. Ausubel FM, Brent R, Kingston RE, Moore DD, Seidman JG, et.al. (1999) Short protocols in molecular biology. (4th edn), Wiley, USA

17. Saavedra L, Taranto MP, Sesma F, de Valdez GF (2003) Homemade traditional cheeses for the isolation of probiotic Enterococcus faecium strains. Int J Food Microbiol 88: 241-245.

18. Aziz RK, Bartels D, Best AA, DeJongh M, Disz T, et.al. (2008) The RAST Server: Rapid annotations using subsystems technology. BMC Genomics 9 : 75.
19. van Heel AJ, de Jong A, Montalban-Lopez M, Kok J, Kuipers OP (2013) BAGEL3: Automated identification of genes encoding bacteriocins and (non-) bactericidal posttranslationally modified peptides. Nucleic Acids Res 41: W448453

20. Solovyev VV, Shahmuradov IA, Salamov AA (2010) Identification of promoter regions and regulatory sites. Methods in Molecular Biology 674: 57-83.

21. Hammami R, Zouhir A, Ben Hamida J, Fliss I (2007) BACTIBASE: a new webaccessible database for bacteriocin characterization. BMC Microbiol 7: 89.

22. Hammami R, Zouhir A, Le Lay C, Ben Hamida J, Fliss I (2010) BACTIBASE second release: a database and tool platform for bacteriocin characterization. BMC Microbiol 10:22.

23. Raya R, Bardowski J, Andersen PS, Ehrlich SD, Chopin A (1998) Multiple transcriptional control of the Lactococcus lactis trp operon. J Bacteriol 180 3174-3180.

24. Suarez NE, Saavedra L, Slozilova I, Bonacina J, Demnerova K, et.al. (2013) Draft Genome Sequence of Enterococcus faecium Strain CRL 1879, Isolated from a Northwestern Argentinian Artisanal Cheese. Genome Announc 1: e514513

25. Whelan JA, Russell NB, Whelan MA (2003) A method for the absolute quantification of cDNA using real-time PCR. J Immunol Methods 278: 261-269.

26. Cintas LM, Casaus P, Havarstein LS, Hernandez PE, Nes IF (1997) Biochemica and genetic characterization of enterocin $\mathrm{P}$, a novel sec-dependent bacteriocin from Enterococcus faecium P13 with a broad antimicrobial spectrum. App Environ Microbiol 63: 4321-4330.

27. Franz CM, Worobo RW, Quadri LE, Schillinger U, Holzapfel WH, et.al. (1999) Atypical genetic locus associated with constitutive production of enterocin $B$ by Enterococcus faecium BFE 900. Appl Environ Microbiol 65: 2170-2178.

28. Hu CB, Malaphan W, Zendo T, Nakayama J, Sonomoto K (2010) Enterocin $\mathrm{X}$, a novel two-peptide bacteriocin from Enterococcus faecium KU-B5, has an antibacterial spectrum entirely different from those of its component peptides. Appl Environ Microbiol 76: 4542-4545.

29. Doi K, Eguchi T, Choi SH, Iwatake A, Ohmomo S, et.al. (2002) Isolation of enterocin SE-K4-encoding plasmid and a high enterocin SE-K4 producing strain of Enterococcus faecalis K-4. J Biosci Bioeng 93: 434-436.

30. Sedgley CM, Clewell DB, Flannagan SE (2009) Plasmid pAMS1-encoded, bacteriocin-related "Siblicide" in Enterococcus faecalis. J Bacteriol 191: 31833188.

31. O'Keeffe T, Hill C, Ross RP (1999) Characterization and heterologous expression of the genes encoding enterocin a production, immunity, and regulation in Enterococcus faecium DPC1146. Appl Environ Microbiol 65 1506-1515.

32. Rogne P, Fimland G, Nissen-Meyer J, Kristiansen PE (2008) Three-dimensional structure of the two peptides that constitute the two-peptide bacteriocin lactococcin G. Biochim Biophys Acta 1784: 543-554.

33. Javed I, Ahmed S, Ali MI, Ahmad B, Ghumro PB, et.al. (2010) Bacteriocinogenic potential of newly isolated strains of Enterococcus faecium and Enterococcus faecalis from dairy products of Pakistan. J Microbiol Biotechnol 20: 153-160.

34. Aymerich T, Garriga M, Ylla J, Vallier J, Monfort JM, et.al. (2000) Application of enterocins as biopreservatives against Listeria innocua in meat products. $J$ Food Protec 63: 721-726.

35. Foulquie Moreno MR, Sarantinopoulos P, Tsakalidou E, De Vuyst L (2006) The role and application of enterococci in food and health. Int J Food Microbiol 106: $1-24$

36. Todorov SD, Dicks LM (2009) Bacteriocin production by Pediococcus pentosaceus isolated from marula (Scerocarya birrea). Int J Food Microbiol 132: $117-126$.

37. Casaus P, Nilsen T, Cintas LM, Nes IF, Hernandez PE, et.al. (1997) Enterocin $\mathrm{B}$, a new bacteriocin from Enterococcus faecium T136 which can act synergistically with enterocin A. Microbiology 143: 2287-2294.

38. Ennahar S, Asou Y, Zendo T, Sonomoto K, Ishizaki A (2001) Biochemical and genetic evidence for production of enterocins $\mathrm{A}$ and $\mathrm{B}$ by Enterococcus faecium WHE 81. Int J Food Microbiol 70: 291-301.

39. Fontana C, Cocconcelli PS, Vignolo G, Saavedra L (2015) Occurrence of antilisterial structural bacteriocins genes in meat borne lactic acid bacteria. Food Control 47: 53-59. 
Citation: Suárez N, Bonacina J, Hebert EM, Saavedra L (2015) Genome Mining and Transcriptional Analysis of Bacteriocin Genes in Enterococcus faecium CRL1879. J Data Mining Genomics Proteomics 6: 180. doi:10.4172/2153-0602.1000180

40. McShan W, Shankar N (2002) The Genome of Enterococcus faecalis V583: a Tool for Discovery: The Enterococci. (ed ASM Press), Washington, DC.

41. Aguilar-Galvez A, Dubois-Dauphin R, Campos D, Thonart P (2011) Genetic determination and localization of multiple bacteriocins produced by Enterococcus faecium CWBI-B1430 and Enterococcus mundtii CWBI-B1431. Food Sci Biotechnol 20: 289-296.

42. Khan H, Flint S, Yu PL (2010) Enterocins in food preservation. Int J Food Microbiol 141: 1-10.
43. Strompfova V, Laukova A, Simonova M, Marcinakova M (2008) Occurrence of the structural enterocin A, P, B, L50B genes in enterococci of different origin. Vet Microbiol 132: 293-301.

44. Nilsen T, Nes IF, Holo H (2003) Enterolysin A, a Cell Wall-Degrading Bacteriocin from Enterococcus faecalis LMG 2333. Appl Environ Microbiol 69: 2975-2984 